\title{
Keeping science's seat at the decision- making table: Mechanisms to motivate policy-makers to keep using scientific information in the age of disinformation
}

\section{OPEN ACCESS}

Citation: Marleau JN and Girling KD. 2017. Keeping science's seat at the decision-making table: Mechanisms to motivate policy-makers to keep using scientific information in the age of disinformation. FACETS 2: 1045| 064. doi: | 0.1 | 39/facets-20 17-0087

Editor: C. Scott Findlay

Received: June 29, 2017

Accepted: October 17, 2017

Published: December 18, 2017

Copyright: (C) 2017 Marleau and Girling. This work is licensed under a Creative Commons Attribution 4.0 International License (CC BY 4.0), which permits unrestricted use, distribution, and reproduction in any medium, provided the original author(s) and source are credited.

Published by: Canadian Science Publishing

\author{
Justin N. Marleau ${ }^{\mathrm{ab} \star}$ and Kimberly D. Girling ${ }^{\mathrm{a} \dagger}$ \\ ${ }^{a}$ Mitacs Canadian Science Policy Fellowship, Mitacs Inc., 5145 Ave Decelles, Montreal, QC H3T 2B2, \\ Canada; ' Department of Biology, McGill University, 1205 Docteur Penfield, Montreal, QC H3A 1B1, \\ Canada \\ *justin.marleau@mail.mcgill.ca \\ ${ }^{\dagger}$ Authors share first author status and their views or opinions expressed within this paper belong solely to \\ the authors and do not represent those of Mitacs.
}

\begin{abstract}
Policy-makers are confronted with complex problems that require evaluating multiple streams of evidence and weighing competing interests to develop and implement solutions. However, the policy interventions available to resolve these problems have different levels of supporting scientific evidence. Decision-makers, who are not necessarily scientifically trained, may favour policies with limited scientific backing to obtain public support. We illustrate these tensions with two case studies where the scientific consensus went up against the governing parties' chosen policy. What mechanisms exist to keep the weight of scientific evidence at the forefront of decision-making at the highest levels of government? In this paper, we propose that Canada create "Departmental Chief Science Advisors" (DCSAs), based on a program in the UK, to help complement and extend the reach of the newly created Chief Science Advisor position. DCSAs would provide advice to ministers and senior civil servants, critically evaluate scientific work in their host department, and provide public outreach for the department's science. We show how the DCSAs could be integrated into their departments and illustrate their potential benefits to the policy making process and the scientific community.
\end{abstract}

Key words: chief science advisor, science policy, open science, open government, departmental chief science advisor, evidence-based policy

\section{Introduction}

Every day, policy-makers at the highest levels of the Canadian government are called upon to develop solutions to complex problems ranging from overdoses caused by opioid addictions to climate change. These individuals must weigh a variety of factors in their decision-making process such as whether a proposed solution is within their mandate, does it conflict with an electoral campaign promise, is it in line with the ideological preferences of the party, and does the public generally accept the proposed solution (e.g., Kingdon 2011). All these factors play a role in whether or not policy-makers are willing to utilize solutions that are proposed to them. 
The solutions proposed may or may not be supported by scientific evidence from the natural and (or) social sciences. For example, subsidies and noncompulsory measures are used to combat climate change and have generally resulted in little to no effective reduction of greenhouse gas emissions, yet they are commonly suggested in the policy arena (Rivers and Jaccard 2009). Furthermore, the scientific evidence can also be swamped out by misinformation or disinformation due to exaggerations in media and press releases, reports, and poor scientific studies (Sumner et al. 2016). Perhaps the most famous case of this is The Lancet paper authored by Andrew Wakefield that falsely linked the mumps-meningitis-rubella vaccine to autism, which has led to plummeting vaccination rates and the re-emergence of outbreaks in multiple communities (Godlee et al. 2011). Being able to discern fact from fiction in the scientific literature is vital, but many policy-makers and the general public are not equipped to do so.

The Council of Canadian Academies (CCA) recently produced a report detailing the state of Canadian science knowledge, and its results are sobering. Although Canada did better than its peers in scientific literacy, only $42 \%$ of Canadians could be considered scientifically literate (Council of Canadian Academies 2014). Although this generally improves with education, that boost is closely linked to additional science courses in university (Council of Canadian Academies 2014). As many senior policy-makers in federal government do not have a scientific education (Table 1), they are likely not well equipped to adjudicate the evidence for themselves and require advice. Without timely access to this advice, policy-makers may focus more on addressing public concerns rather than what is the best-supported policy. Furthermore, it would also be beneficial to have these advisors play a role in improving the public's scientific literacy surrounding policy debates through supporting outreach and education initiatives.

The Canadian government is addressing this concern in part through the creation of a Chief Science Advisor (CSA) who reports directly to the Minister of Science and the Prime Minister. Although this is a good start, we believe that more is needed to ensure access to the best scientific advice throughout government. In this paper, we will argue that Canada would benefit from creating "Departmental Chief Science Advisors (DCSAs)", which is inspired by the UK's scientific advice model and has also been adopted in New Zealand.

We first consider two examples of how science advice either led to evidence-based policy or was ignored to show the potential and limitations of science advice in policy making. We then outline the general function of a CSA based on comparisons among multiple countries. We follow with an explanation of our proposed DCSAs, how they would function in government, as well with how they would differ from those found in New Zealand and the UK. We then conclude with how this model

Table 1. Education background of senior decision-makers within the Federal Science Portfolio in June 2017.

\begin{tabular}{lcc} 
Position & $\begin{array}{c}\text { Number with STEM } \\
\text { Bachelor's degree or higher }\end{array}$ & $\begin{array}{c}\text { Number with STEM } \\
\text { PhD or equivalent }\end{array}$ \\
Minister & $2 / 9$ & $2 / 9$ \\
Deputy Minister & $5 / 10$ & $3 / 10$ \\
\hline
\end{tabular}

Note: The relevant departments and agencies are the Canadian Food Inspection Agency, the Canadian Nuclear Safety Commission, the Canadian Space Agency, Agriculture and Agri-Food Canada, Environment and Climate Change Canada, Fisheries and Oceans Canada, Health Canada, National Research Council Canada, Natural Resources Canada, and the Public Health Agency of Canada. Multiple departments and agencies share a Minister, and some have multiple Ministers. Each Minister is counted only once.

${ }^{a}$ STEM stands for Science, Technology, Engineering, and Mathematics. 
would help maintain strong scientific advice within government and provide opportunities to improve scientific literacy in the public discourse compared with previous models of science advice in Canada.

\section{Bringing science advice to policy changes: Its influence or lack thereof}

Getting scientific advice to policy-makers can be a challenge, but does it make an impact on decisionmaking once it gets to them? The answer to this question is highly complex and contingent on a number of factors such as the organizational structure, priorities, and capacity within which the decisionmaker is imbedded (Ntshotsho et al. 2015). These priorities can be set through policy making within political parties that establish their electoral platforms. As any member of the public can join a political party and participate in their internal policy debates, the scientific literacy of these party members may be lacking (Council of Canadian Academies 2014).

This process can lead to the parties adopting policies that are developed to appease misinformed concerns about safety, harms, and benefits. For example, the Parti Québecois in its party platform ${ }^{1}$ calls for the banning of fluoride in drinking water, which goes against the consensus of both global and national health authorities (Health Canada 2011; O'Mullane et al. 2016). When the Parti Québecois came to power in 2012, a petition to implement this policy reached the National Assembly (the provincial parliament) and caused the Commission de la santé et des services sociaux to study the issue.

This parliamentary committee received submissions from a number of groups, including supporters of the petition such as the Front commun pour une eau saine, and objectors such as L'Ordre des dentistes du Québec. Both sides submitted articles and documents from the scientific literature, though the quality and relevance to the issue at hand varied significantly. However, one of the most important sources of scientific advice and information to the parliamentary committee was l'Institut national de santé publique du Québec (INSPQ). INSPQ was founded in 1998 as a Crown corporation to provide support to the Québec's Minister of Health and Social Services (MSSS) and other health authorities through research, expert advice, and laboratory services.

INSPQ provided critical science and ethics evaluation of both the current practices of the MSSS in water fluoridation and the submissions to the committee. In particular, INSPQ refuted a number of claims of the supporters of the ban as the levels of fluoride used in Quebec $(0.7 \mathrm{mg} / \mathrm{L})$ are much less than those that cause significant health problems (McDonagh et al. 2000; O'Mullane et al. 2016). They also advised in their reports that the current system was ethically and scientifically sound and recommended its continuation (Institut national de santé publique du Québec 2007a; Comité d'éthique de la santé publique 2012).

The scientific evidence in favour of expanding fluoridation programs to reduce tooth decay in children swayed the parliamentary committee (La Commission de la santé et des services sociaux 2013). The parliamentary committee's conclusions led Québec's Minister of Health to reject the position of his own party on water fluoridation. The intervention of INSPQ played a key role in this change in policy, which was noted in the report of the parliamentary committee when it discussed the harms of fluorosis (La Commission de la santé et des services sociaux 2013).

The about-face by the Parti Québecois on water fluoridation in the face of scientific advice and evidence stands in stark contrast to the response of the former federal Conservative government's position on safe injection sites. Canada's first safe injection site, Insite, was founded in 2003 to help

\footnotetext{
1“Article 5.6 t): Modifiera la loi pour interdire la fluoration de l'eau potable”; pq.org/programme/\#c-5-6.
} 
combat the drug overdose and HIV/AIDS crises in Vancouver, British Columbia (Dooling and Rachlis 2010). Safe injection sites are based upon the principle of harm reduction, and Insite provides access to clean needles, medical supervision, and treatment programs to reduce overdose deaths and the spread of infectious diseases (Dooling and Rachlis 2010). In 2003, Liberal Health Minister Anne McLellan used her ministerial discretion in section 56 of the Controlled Drug and Substance Act to grant a temporary three-year exemption to Insite from drug possession and trafficking penalties to allow scientific evaluation of a safe injection site in Canada (Dooling and Rachlis 2010).

Since the creation of Insite, researchers from the B.C. Center for Excellence in HIV/AIDS have monitored it to evaluate its effectiveness. The earliest studies noted that Insite did not lead to increased drug use (Kerr et al. 2006a), prevented any overdose on site from becoming a fatality (Kerr et al. 2006b), led to a reduction in public drug use (Wood et al. 2006), led to reduced needle sharing (Wood et al. 2006), and led to an increase uptake of detoxification treatment programs for drug users (Wood et al. 2006). Furthermore, there was no indication of any increase in criminal activities around Insite (Wood et al. 2006).

Despite the early evidence in favour of maintaining the program, Insite entered into a period of great uncertainty due to the change in government. After defeating the Liberals in 2006, the Conservative government was faced with an expiring exemption. Conservative Health Minister Tony Clement decided to temporarily extend the exemption until 2008 to allow for greater study (Health Canada 2006). During this period, the Royal Canadian Mounted Police funded multiple studies to critique Insite, though only two were eventually published in an online journal that does not require peer review (Dooling and Rachlis 2010; Geddes 2010). Minister Clement alluded to these studies during a speech by at the 2007 Canadian Medical Association Annual Meeting where he mentioned "academic debate" concerning the evidence in support of Insite (Kondro 2007; Dooling and Rachlis 2010).

Additionally in 2007, Minister Clement created a Health Canada expert advisory committee to evaluate Insite (Dooling and Rachlis 2010). This expert advisory committee's role was to develop a research plan on safe injection sites and to summarize the current state of research based around the objectives of Insite (Health Canada 2008). However, the committee was not responsible for providing recommendations regarding policies and had no decision-making role (Health Canada 2008). The expert advisory committee's findings were generally in support of the conclusions found in previous studies (Health Canada 2008). However, the report also concluded a lack of evidence for a reduction of drug use and efficacy in saving lives, which was seized upon to justify rejecting an extension of the federal drug exemption for Insite (Dooling and Rachlis 2010).

Despite the desire to close Insite, the Conservative government suffered multiple defeats in the courts, resulting in a landmark 2011 ruling that forced the Health Minister to grant Insite a permanent Section 56 exemption as its denial violated the Charter rights of the users. ${ }^{2}$ These legal defeats did not stop ongoing attempts to prevent the opening of additional safe injection sites, despite new evidence continuing to support Insite (e.g., Andresen and Boyd 2010; Marshall et al. 2011). Only a change in government in 2015 led to a change in policy surrounding safe injection sites in Canada.

What can help explain the different outcomes for the policies? One hypothesis could be the differing mechanisms for science advice. For water fluoridation, INSPQ was empowered by legislation not only to provide advice, but also to make recommendations to the Minister and the MSSS regarding policies and to provide a challenge function within the government. The expert advisory group for safe injection sites, in contrast, was not mandated to make recommendations, which greatly limited its ability

${ }^{2}$ Canada (Attorney General) v. PHS Community Services Society, 2011 SCC 44, [2011] 3 S.C.R. 134. 
to influence policy. In addition, INSPQ was a permanent body that continuously reviews and investigates health policy issues, whereas expert advisory groups are temporary bodies that disperse after issuing their reports.

However, there was also a commonality between safe injection sites and water fluoridation: misinformation. In both cases, studies of questionable quality were used to try to influence public opinion and policy-makers. For the fluoridation case, INSPQ critiqued submissions to the parliamentary committee that misrepresented the potential harms of low levels of fluoride in water (e.g., neurotoxicity, bone fragility; INSPQ 2007b). For Insite, papers that may not have been peer reviewed received outweighed attention from the ministry despite the questionable reliability of the studies (Dooling and Rachlis 2010; Geddes 2010). For the public and policy-makers, it is not always easy to discern which journals are publishing peer-reviewed, credible papers and which are not. Similarly, strong emotions about conflicting issues can sway the opinions of the public, and the decision-makers that govern them. Furthermore, poor papers can slip through the cracks of peer review on occasion, which necessitates an expert eye for understanding the methodological issues involved.

\section{Expert advice down the hall: CSAs}

Barriers such as disinformation, low public literacy, and a paucity of scientific expertise among decision-makers can prevent good science from informing government decisions. One way to mitigate this is through dedicated science advisory programs embedded in government. An existing model that is currently implemented in countries such as New Zealand (Office of the Prime Minister's Science Advisory Committee 2017), the UK (UK Government Office for Science 2015), and Australia (Australian Government 2017) is the employment of CSAs (Quirion et al. 2016).

The CSA (or Chief Scientist, in some cases) is selected based on scientific expertise and excellence and is an appointed, nonpartisan official that serves as the Prime Minister's and Cabinet's personal consultant on scientific and technological issues and policies. The CSA may be drawn upon to assess or produce scientific content and reports and can help identify new opportunities or dangers. The CSA also plays a key role as a public-facing authority on science. They may deliver national scientific addresses and reports, make sound science available to the community, and foster public understanding of scientific issues of importance.

As a neutral public servant, the CSA can facilitate strong interdepartmental and cross-government relationships, collaborations, and strategic coordination on scientific topics, and they may also advise on ongoing events or conflicts (UK Government Office for Science 2015; Office of the Prime Minister's Science Advisory Committee 2017). Although the CSA is not a decision-maker, they have an important function to advise on and challenge scientific evidence and decisions, ensuring that decisions are made with the best evidence possible. To achieve their objectives, the CSA typically oversees an office of personnel, aiding in research, communications, education, and administration (UK Government Office for Science 2015; Australian Government 2017; Office of the Prime Minister's Science Advisory Committee 2017).

The impact of the CSA on national outcomes can be significant. To revisit a previous example, in 2014, in response to ongoing concerns about water fluoridation, the CSA office in New Zealand was requested by the Auckland Council Chief Planning Committee to advise on the potential health impacts of water fluoridation. Using detailed scientific evaluation, the CSA and an appointed panel produced a publicly accessible report reviewing the existing scientific literature that ended up accompanying and supporting a report by the Minister of Health (Moore and Poynton 2015). In the report, the panel weighed the evidence supporting the benefits of fluoride on dental health and the existing scientific data on potential public health risks. 
Unanimously the panel concluded that the benefits of fluoridation greatly outweighed the potential health risks, and the panel urged against defluoridation (Office of the Prime Minister's Science Advisory Committee 2014). This report was followed by further documentation from New Zealand Cabinet strongly urging community water fluoridation as a cost-effective means of improving oral health (Cabinet Social Policy Committee 2017). With the support of strong evidence, the Auckland Regional Public Health Service released the Health (Fluoridation of Drinking Water) Amendment Bill in 2017 (Auckland Regional Public Health 2017), which transferred decision-making power on water fluoridation from territorial authorities to Departmental Health Boards. Although debates on water fluoridation continue in New Zealand, bodies such as the CSA office have a strong and influential voice in the discussion.

\section{Science advisory structures in Canada}

Although countries such as New Zealand and the UK employ federal CSAs to deliver scientific consult, science advice is provided to government through various avenues in other countries, including societies or academies, advisory councils, formal panels (called upon for specific topics), or committees. Scientific advice has a long history in Canada. In the 1960s, the Canadian federal government implemented a Science Secretariat in the Privy Council Office, which served to advise Cabinet on scientific issues. The implementation of the Science Council of Canada (SSC), an advisory committee of appointed scientists and government officials acting independently to consult nationally on science, identify opportunities and challenges, and promote science education, soon followed (Steed and Millin 2005).

In 1969, a CSA was appointed to lead the Science Secretariat (Senate Special Committee on Science Policy 1970). However, this move was nullified in 1971, with a government shift to a Ministry of State for Science and Technology (Grove 2006; Quirion et al. 2016). The SSC was also abandoned in 1992 (Dufour and de la Mothe 1993). In 2000, via the Council of Science and Technology Advisors (CSTAs), Canada initiated a new scientific advisory initiative through the Science Advice for Government Effectiveness program, the principles of which were analogous to existing CSA guidelines currently implemented in the UK and New Zealand (Quirion et al. 2016; Office of the Prime Minister's Science Advisory Committee 2017). Unfortunately, the Federal government abolished the CSTA in 2007, leading to a repeal of these advisory principles and the scientific advisory roles that enforced them (O'Hara and Dufour 2014). The formation of a National Science Advisory office in 2003 was another short-lived attempt for federal science advice within Cabinet; however, after several shifts in structure, it too was terminated in 2008 (Quirion et al. 2016).

Presently in Canada, several bodies and individuals provide science advice and support to government. The CCA, an arms-length, independent, not-for-profit organization, is regularly recruited by Cabinet to carry out reports on requested scientific topics. Similarly, the Science, Technology and Innovation Council (STIC), another independent organization, is mandated by the government to produce confidential advice on issues of science, technology, and public policy. In addition, Chief Scientists and Assistant Deputy Ministers (ADMs) in Canadian science-based departments and agencies help guide departmental strategies and scientific activities. All these positions and organizations signal a desire for advice on science policy within the government, though their effectiveness varies (Hutchings and Stenseth 2016).

In 2015, the election of the Trudeau Liberals ignited a new desire for embedded government scientific advice in Canada, with a platform focused on evidence-based policy, unmuzzling of scientists, and open access to government science (Liberal.ca 2015). In an effort to further support and enforce these goals, in December 2016, the Minister of Science Kirsty Duncan announced a public call for a new Canadian Federal CSA, whose role will be to directly advise the Prime Minister and 
Cabinet on scientific topics, provide publicly accessible information on scientific issues of importance, promote scientific transparency and access, and evaluate scientific projects (Government of Canada 2017a). On 26 September 2017, Dr. Mona Nemer was appointed as the Chief Science Adviser of Canada.

\section{DCSAs: An improved approach?}

On 22 April 2017, Canadians from all across the country took to the streets in an international "March for Science" to protest international government science cuts and voice support for evidence-based decision-making. Organizations like the International Network for Science Advice (INGSA), an international platform for capacity building, exchange, and networking are only growing (INGSA 2017). Although good science should never supplant decision-makers, it is clear that there is an appetite for effective government science advisory networks. The question of how to effectively implement science advice is a challenging one (Hutchings and Stenseth 2016).

The appointment of Dr. Mona Nemer as the federal CSA is a strong step towards safeguarding evidence-based science and policy in Canada. However, relying on a single advisor to broadly advise on science in Canada may present a challenge given the enormous diversity in scientific profiles between government departments and the large number of ongoing departmental decisions that require scientific input. In addition, the complicated chain of communication from lower levels of government to the House of Commons may mean that specialized scientific issues within departments may not effectively arrive at nor directly benefit from the input of a government-wide CSA.

Instead, there may be additional advantages to expanding the Canadian advisory structure by having additional scientific advisors with specialized expertise embedded within individual departments. Similar advisory structures already exist elsewhere. In countries such as the UK (UK Government Office for Science 2015), DCSAs work in concert with the federal government CSA and mirror their role at the departmental level ensuring that individual departmental decisions are being made with support of sound scientific evidence (UK Government Office for Science 2015).

Although their specific responsibilities vary across departments, DCSAs act as senior departmental officers, work closely with department ministers and senior directors, review scientific evidence of interest to the department, ensure mechanisms are in place to implement evidence-based policies, and establish cross-government collaboration and coordination (UK Government Office for Science 2015). By facilitating a strong network of science advice across the country, DCSAs can directly support the mandates and goals of the government-wide CSA, while also providing specialized input and support directly to the department they belong to.

\section{A model for departmental science advice in Canada}

Given the recent appointment of the Canadian CSA and the success of existing department science advisory models, we propose herein that DCSAs could provide additional advantages to the existing scientific decision-making process in Canada. To illustrate the potential outcomes of such a program, we have generated a hypothetical framework of departmental science advice in Canada, drawing upon current mandates of CSAs around the globe, as well as the existing DCSA program structure in the UK (UK Government Office for Science 2015) as a model. This framework could serve as a basis to help fulfill Recommendation 4.5 of Canada's Fundamental Science Review (Naylor et al. 2017). In the following section, we will outline our potential framework for the implementation of a Canadian DCSA program, discuss the implications and benefits of such a change, and propose a reasonable budget and timelines. An overview of our model can be found in Fig. 1 . 


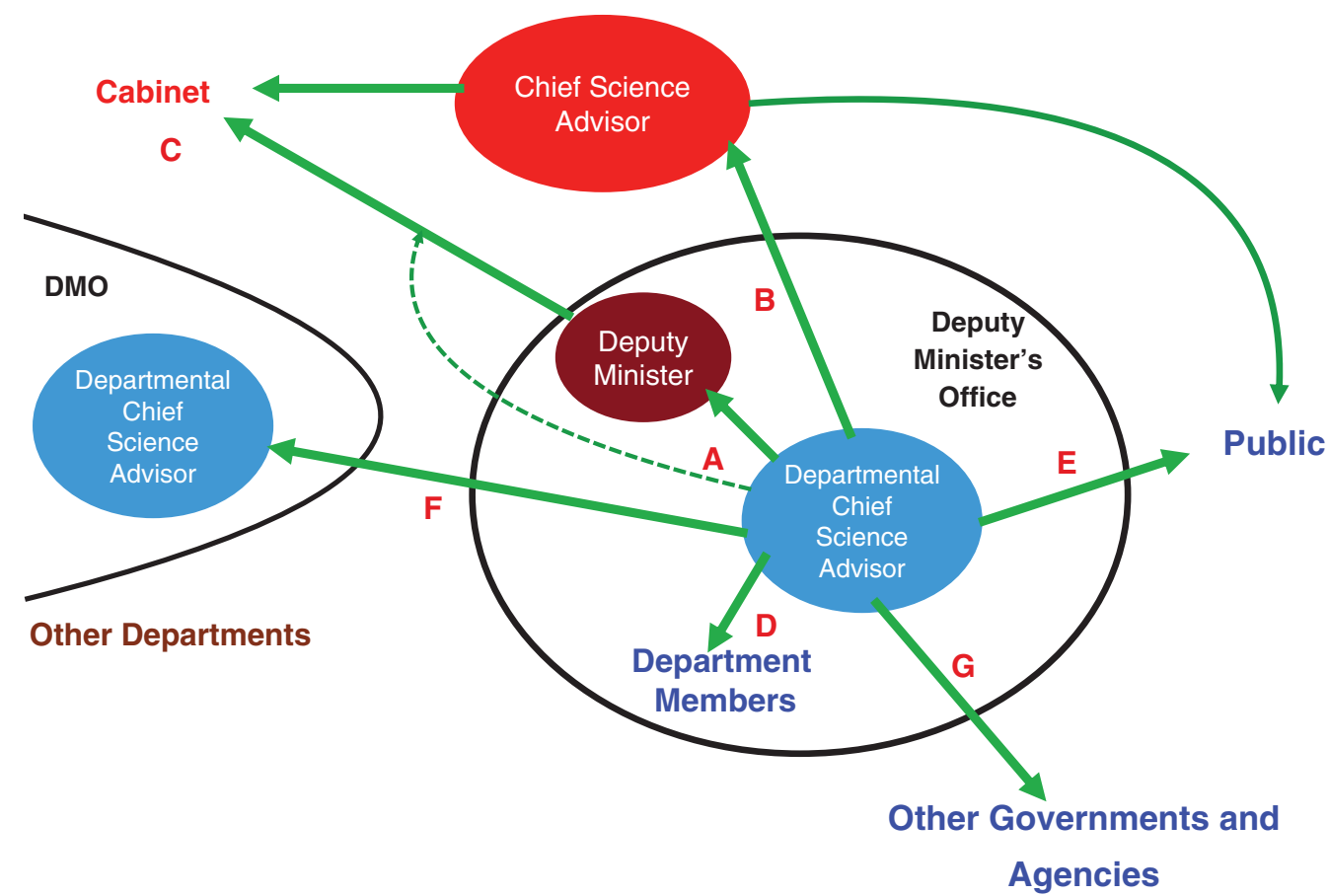

Fig. 1. A model for the proposed Department Chief Science Advisor (DCSA) Office. Each department in the Science Portfolio Plus would employ a DCSA, situated in the Office of the Deputy Minister (DM). The DCSA would oversee an office of support staff (not pictured). (A) The DCSA advises on departmental scientific issues directly to the DM. This may include assessing and (or) challenging scientific evidence, counselling on scientific policies and decisions, producing scientific reports, or advising on opportunities or risks. (B) The DCSA may also act to support and advise the government CSA on departmental science issues. (C) The DCSA may have direct influence on Cabinet decisions via the DM and the CSA and their respective chains of command, but may also be requested to provide advice directly to the department's minister(s). (D) The DCSA may also provide advice down the reporting chain within the department. (E) The DCSA is a public-facing public servant and communicates government science to the public through comprehensive documentation and public addresses and may further improve community science literacy through science advocacy and education opportunities. (F) The DCSA may work interdepartmentally through collaboration and communication with DCSAs in other science-based departments and agencies, facilitating open science and sharing expertise and opportunities. (G) They may also connect with or observe other governments, agencies or players, identifying opportunities and (or) risks, and facilitating strong international and global collaborations.

\section{Roles of a Canadian DCSA}

Unlike the government-wide CSA, DCSAs are positioned to work on scientific projects relevant to specific departments. Thus, their role may be to mirror and support the CSA at a departmental level by drawing from their relevant expertise. Based on existing CSA and DCSA formats as well as the current Canadian government structure and mandates, we propose that the precise role of a DCSA in Canada could include a number of the following functions, with variations based on specific departmental need.

\section{Provide informed scientific advice on departmental projects, issues, and policies}

A primary role of the DCSA would be to provide advice and guidance on scientific issues of importance to the department. The DCSA may be consulted for their input on scientific decisions and 
policies to ensure that they are made with sound scientific support and may help resolve uncertainties by reviewing and providing scientific evidence. The DCSA may be requested to produce commissioned scientific reports and documentation on topics of importance to the department. Situated in the office of the Deputy Minister (DM), the DCSA could directly consult the DM on departmental issues, while their positioning could also facilitate communication up the chain of command to the Minister and Cabinet, or down the chain to the ADMs, Directors, and their staff. The primary role of the DCSA could be categorized as a "science for policy" role rather than developing "policy for science". However, there are possibilities for the development of science policy depending on the qualifications and background of the DCSA.

The DCSA may also be drawn upon for advice and input on specific projects, policies, or departmental portfolios from the government CSA. DCSAs for individual departments would be selected, based on their expertise in a field related to departmental priorities, to provide specialized and relevant advice to matters of importance within the department. The DCSA may also oversee an office of scientists, trainees, human resources, and communications professionals to help them achieve this goal of providing informed and high-quality scientific counsel.

\section{Be a public-facing scientific advisor at the departmental level}

The DCSA, not unlike the CSA, would have an important function as a public-facing scientific representative for the department. They may be responsible for producing publicly accessible and comprehensive documentation on scientific matters, giving public addresses, responding to public concerns, or creating opportunities and (or) events for education and outreach in the community. In doing so, the DCSA could play a key role in fostering public understanding of key issues, advocate for education, and improve science literacy.

\section{Create strong interdepartmental collaboration and communication on scientific issues}

Implementation of DCSAs within the Canadian science portfolio could allow for the formation of a network of DCSAs across all scientific departments that meets regularly. This "Science Advisory Network", chaired by the government CSA, could facilitate improved collaboration across departments, present opportunities for partnership and assistance across government, identify risks and challenges, and share their diverse competencies.

\section{Challenge scientific evidence and decisions}

As a nonpartisan, embedded individual, the DCSA could exercise a unique challenge function to government decisions and functions. This may include identifying decisions that require more robust scientific support, screening existing evidence for fallibility or "disinformation", giving input during discord, and providing a critical eye to ongoing scientific decisions and issues.

\section{Identify opportunities and risks through government, international, and nongovernment connections}

The DCSA, through connections with and horizon scanning of the local and global scientific landscape, may help identify new challenges and opportunities for innovation, as well as emerging risks and concerns on issues related to the department. To do so, the DCSA may act as a point of contact to private sector parties, academia, international partners (including other governments), nongovernment organizations, industry, and the broader scientific community. This function may also include leveraging their personal or professional networks. 


\section{Enforce departmental mandates for open science and data accessibility}

The federal government has recently implemented clear priorities for open science and data accessibility to fulfill the Open Government Directive (Government of Canada 2014; Office of the Prime Minister of Canada 2015). As a senior scientific official for the department, the DCSA may take on the responsibility to ensure that the department is adequately meeting these objectives.

\section{Represent the department on scientific committees, networks, and collaborations}

The DCSA's unique role as a public-facing member of government and as a cross-departmental connection with other DCSAs can help facilitate this goal through public and interdepartmental sharing of scientific findings.

The DCSA may be requested to sit on national or international committees that are relevant to the scientific needs of the department. They may also need to represent the DM or department on science issues on panels or collaborations.

\section{Provide advice and guidance during times of emergency}

The DCSA may be called upon to give counsel on ongoing crises, disasters, or emergencies, or during times of national uncertainty.

\section{Foster new opportunities for training and talent acquisition}

The DCSA would require support from an office staffed by scientific experts and other professionals. This may include scientific trainees in academic programs or postdoctoral fellows. By supporting academic studentships and bringing together an office of talented science professionals, the DCSA may present new opportunities to bring talented individuals to the public service, particularly those with a strong scientific background.

It is important to note that the role of a DCSA is not that of a decision-maker, but rather is an independent voice to advise on key issues, challenge scientific content, and provide nonpartisan and robust scientific input to questions of importance to the department. This is in contrast to current ADMs of science and technology branches or Chief Scientists within government departments and agencies.

These officials, unlike the DCSAs, are decision-makers and are directly responsible to their Ministers and DMs. ADMs and Chief Scientists manage staff and budgets and they implement departmental science policies and programs based on operational needs, ministerial mandate letters, and the mandate of the department (Enros 2013). They can also play an advisory role, but the advice need not originate with them or their office, but rather their subject-matter experts or policy analysts within their branches and divisions. ADMs, in particular, may not have a scientific background or have a background in a scientific field that is irrelevant to their departmental work.

\section{Initial uptake of DCSAs: Science portfolio "Plus"}

Although implementation of DCSA positions in all government departments may provide some advantages, we propose that initial uptake of DCSAs in Canada should focus specifically on departments where the need for science advice is most pressing. Presently, the Federal Science Portfolio of Canada (Shared Services Canada 2016) includes the following departments: Canadian Food Inspection Agency, Canadian Nuclear Safety Commission, Canadian Space Agency, Agriculture and 
Agri-Foods Canada, Environment and Climate Change Canada, Fisheries and Oceans Canada, Health Canada, National Research Council of Canada, Natural Resources Canada, and the Public Health Agency of Canada. Given the clear focus of these 10 departments on issues of critical scientific importance, we recommend the primary implementation of one DCSA in each.

We also suggest that a number of other departments may likewise benefit from the specialized science advice provided by a DCSA, given their focus on issues related to science or technology. This list includes the Department of National Defence and the Canadian Armed Forces; Innovation, Science and Economic Development Canada; Public Safety; Crown-Indigenous Relations and Northern Affairs Canada; Statistics Canada; and Transport Canada. Initiating departmental science advisory programs in this Science Portfolio "Plus" could not only help ensure the delivery of robust, evidence-based decisions within these departments on important scientific issues, but also ensure more facilitated scientific collaboration between departments and across government.

\section{The DCSA office structure}

Similar to the UK Departmental Science Advisory program, we envision Canadian DCSAs to act as a senior official for the department in which they reside. DCSAs should be positioned in a way that their access to their own departmental offices, officials in other departments, and members of Parliament are maximized. Therefore, we suggest that the office of the DCSA should reside within the Office of the DM. Via the DM, the DCSA would have direct access to the Minister, allowing them to access and advise on departmental issues of importance to the ministry, while simultaneously connecting directly with the lower tiers of the department, via the ADMs or Director Generals. Similarly, the DCSA could connect to Cabinet through the CSA via the Science Advisory Network (see "Roles of a Canadian DCSA").

Akin to CSA (or Chief Scientist) offices in New Zealand, the UK, or Australia (UK Government Office for Science 2015; Australian Government 2017; Office of the Prime Minister's Science Advisory Committee 2017), the DCSA may oversee a number of employees, including communications specialists, scientific experts, researchers, analysts, and (or) administrative experts. Collectively, the members of the DCSA office may provide advice and input, assess scientific content, review policies and mandates, produce reports and reviews, and communicate with other offices and stakeholders.

Similarly, the office could employ scientific trainees or postdoctoral fellows, which may provide new opportunities. For example, the Mitacs Canadian Science Policy Fellowship (Mitacs 2017), founded in September 2016, aims to form strong relationships between academia and government and enhance evidence-based science policy by matching recent $\mathrm{PhD}$ graduates with government agencies to work on federal (and soon provincial) policy challenges. Currently, various offices throughout the public service employ fellowship holders. However, a future DCSA office, given the diversity of scientific profiles and responsibilities, may be a potential home for Mitacs fellows. This would provide a new avenue for engaging scientists from academia directly with government science policy (a path that is not always straightforward), and it also brings outside scientific expertise into the public sector.

Another training opportunity that we propose may arise from the DCSA office is modeled after the UK POST note program (UK Parliament 2017). The POST program was designed to deliver short, comprehensive overviews of scientific concepts that may have important public policy implications. These four-page briefings ("POSTnotes") are designed to inform Parliamentarians and are publicly accessible. In the UK program, $\mathrm{PhD}$ fellows on three-month assignments produce POSTnotes. These students conduct research, interview stakeholders and experts, and draft the report that is then extensively peer reviewed and published (UK Parliament 2017). Given our proposed role of DCSAs in 
producing clear and informative scientific documentation available to Parliament and the public, we suggest that a similar program could also be implemented in the DCSA office to contribute to internal evidence-based science policy advice and to improve general scientific literacy.

\section{Selection process and appointments of a DCSA}

To construct a hypothetical DCSA model, we must also consider how candidates are selected and retained. In the existing departmental science advisor program in the UK, DCSAs are appointed to the position through a recruitment process one year in advance (UK Government Office for Science 2015). This call is made publicly to ensure an unbiased pool and to encourage diversity of applicants from a wide range of disciplines and backgrounds. Currently, this adjudication process is undertaken by the existing DCSA and their office; however, for an inaugural DCSA program in Canada, we foresee that the selection process could be overseen collectively by the government CSA, the department's Minister, the DM, and outside experts drawn from civil society.

In the UK, the currently appointed DCSAs come primarily from academic professorships, with a number from industry or other professional institutions (GOV.UK 2017). Applicants are selected based on their specific scientific expertise and its relevance to the department and its priorities (UK Government Office for Science 2015). We propose that Canada adopts a similar DCSA recruitment and appointment process. Although some scientific advisory programs, including the UK, do not have fixed terms for a DCSA (UK Government Office for Science 2015), we proposed that Canadian DCSA appointments be three-year postings, renewable one time, in the case of ongoing projects or portfolios. This could help ensure that advice and expertise being brought into the department is always up to date, facilitate new perspectives, and allow more flexibility of appointees, who may have ongoing career goals.

During their appointment, most UK DCSAs continue to hold their professional or academic appointment in conjunction with their role as a departmental advisor, which is a process that we suggest could also be utilized in Canada (GOV.UK 2017). This co-appointment not only supports the appointed advisor in their career ambitions and allows ongoing productivity, but also ensures that they have continuing connections with and support from their field of expertise, a tool that can further improve their contribution to the public service.

\section{Budget and timelines: Implementation of a DCSA program}

Given the scope of the proposed project, we anticipate that implementation of an inaugural DCSA program in Canada would require $\$ 8.5$ million CAD per year in investment over the course of the next five years, for a total of $\$ 42.5$ million CAD. We arrived at this figure by considering a base annual stipend of up to $\$ 100000$ CAD for each DCSA over the 17 portfolios in the Science Portfolio "Plus". Each DCSA office may also be comprised of two or three employees, at an estimated cost of $\$ 350000$ CAD for salaries and benefits. We also budgeted $\$ 50000$ CAD for each DCSA office to include office equipment, rent, and overhead. We suggest that initiation process would take place over the next three years to facilitate the obtaining of budgetary resources. This timeline also allows one to two years for the government to implement the CSA and its office. This ensures that the CSA program is running smoothly before the initial DCSA call is put forward.

\section{Why DCSAs? Benefits, costs, and implications}

In the previous sections, we have outlined how we envision the implementation of the DCSA program, but we need to return to the question of "why". We believe that the benefits of the DCSA program, which we have enumerated in Table 2, outweigh its cost. Furthermore, the benefits of the DCSA program also address a number of deficiencies of the previous advisory programs. 
Table 2. Benefits of the Departmental Chief Science Advisor (DCSA) program to Canada.

\section{DCSA responsibility}

Provide informed scientific advice to the department

Be a public-facing scientific departmental representative

Challenge scientific evidence and decisions

Connection with science-based departments and agencies, international partners, and other sectors

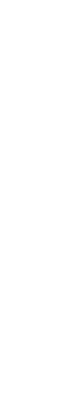

Provide advice and guidance during times of emergency

Support government science opportunities

Non-role-specific benefits

Enforce departmental and federal science mandates

\section{Benefits to Canada}

- Ensures that high-quality science is used to inform policy making process

- Provides improved access to comprehensive and informed scientific documentation

- Supports challenging scientific decisions from a nonpartisan perspective

- $\quad$ Specialized expertise, relevant to department

- Conflict resolution

- Improved public access to robust science

- Improves science literacy, education, and engagement

- Facilitates open access to government science

- Identifies opportunities for collaboration and innovation

- $\quad$ Identifies potential risks

- Keeps the department up to date on ongoing science locally and globally

- Improves government partnership with industry, academia, other governments, and other sectors

- Creates better cross-government relationships and opportunities, through a network of scientific experts

- Circumvents the dissemination of poor science or "disinformation"

- $\quad$ Ensures robust evidence informs key decisions

- $\quad$ Fosters science literacy in the public sector

- Act as a nonpartisan consultant

- Advocates for open science and data accessibility in the public sector

- Supports mandates for evidence-based policy, innovation, and good practices

- $\quad$ Brings independent advice during times of conflict and (or) crisis

- Scientific representative for the department on committees

- Introduces opportunities to bring new trainees, specialists, and scientists to the public sector

- $\quad$ Allow opportunities for early-career researchers to participate due to nonvoluntary nature of position

- Allow for representation and access across regions

- $\quad$ Allow for diversity in position staffing

Note: We propose that implementation of a DCSA program in Canada may provide several key benefits to the existing government decisionmaking process and to the scientific landscape within the public sector. We have summarized these benefits, directly correlated to the proposed roles of a DCSA in Canada. 
The most recently created science advice programs, such as the CCA and STIC, have limited mandates and scope for providing advice and (or) public outreach. The CCA can only review requested topics and cannot provide recommendations (Quirion et al. 2016), whereas the STIC is bound by confidentiality and only provides public reports once every two years (Science, Technology and Innovation Council 2015). The DCSAs, because of their placement inside the DM office, will be able to provide the public outreach of the CCA while also being able to provide internal advice and recommendations like the STIC (Table 2).

The placement of the DCSAs within the governance structure is a key feature that differentiates it from previous advisory bodies. The CSTAs reported directly to Cabinet and the STIC reported to the Minister of Industry (Quirion et al. 2016), whereas the DCSAs would report to Cabinet, DMs, and the CSA, while also providing information to other DCSAs (Fig. 1). This structure provides opportunities to allow for a government-wide approach to science advice, such that both the bureaucracy and politicians are well informed on evidence-based policy (Table 2). Furthermore, while existing departmental chief scientists and elected officials will continue to make key decisions and support scientific activity, the employment of DCSAs to provide council and support and to improve coordination across departments can bolster these existing frameworks.

For example, in the case study of Insite, DCSAs within Health Canada and the Public Health Agency of Canada could have played a pivotal role. First, they could have made recommendations rather than noncommittal conclusions to help prod the government to respond to the evidence. Second, by being a semi-permanent fixture within the government, the DCSAs could continue to update its recommendations as new evidence is brought in and would be able to advise policy-makers throughout the department. Third, by having a public-facing role, the DCSAs could help with outreach with stakeholders and the public by providing a nonpartisan view on Insite, which could lead to the dispelling of myths and misinformation.

Beyond these direct benefits, there are other benefits that could emerge through this program. Because of the remunerated nature of the DCSA positions that allow for the holder to maintain an academic appointment, it is likely that early-career scientists would be enticed to apply for them. One striking example of the lack of early-career scientists within the scientific advisory apparatus was for the Advisory Panel for the Review of Federal Support for Fundamental Science. Only one member of the Advisory Panel was under the age of 50 and no member was under the age of 40 . Adding representation of early-career researchers to the scientific advisory apparatus could help with identifying emerging trends in fields and provide a different perspective from their more senior colleagues.

Furthermore, by having many DCSAs, it will be possible to have both regional and cultural diversity within the "Science Advisory Network" (Table 2). A single CSA can only be a member of one cultural community and would be from one part of the country. With DCSAs, representation from each province is an achievable goal. Furthermore, some of the DCSAs may be better placed in the regions if a department is mostly based in specific location outside Ottawa, such as the headquarters of the Canadian Space Agency in Saint-Hubert, Québec. Recruiting scientists from under-represented groups to ensure the diversity of voices within the scientific community is well represented in providing scientific advice can also be combined this regional diversity.

Of course, there are also additional costs to be considered relative to other science advisory bodies. One cost is the time and effort needed to implement the DCSA program. Unlike voluntary advisory bodies that meet periodically and produce sporadic reports, DCSAs will require significant logistical support to allow them to succeed in their functions and hence the need for dedicated staff. There would also likely be higher human resource needs for DCSAs versus voluntary bodies during the appointment process due to its competitive nature. In addition, the public-facing aspect of the 
DCSA position would require effective media and communication professionals. There would also be greater consequences from the resignation of a DCSA because of their central role within their home department.

The monetary investment into a DCSA program can be viewed as high compared with other science advice programs funded by the Canadian government. For example, the new CSA has an annual budget of $\$ 2$ million CAD (Government of Canada 2017b), whereas the CCA receives $\$ 3$ million CAD per annum (Naylor et al. 2017). However, the amount per department involved (\$500 000 CAD) is a fraction of their annual budgets such as $0.1 \%$ for the Canadian Food Inspection Agency because its annual budget is over $\$ 650$ million CAD (Canadian Food Inspection Agency 2016). Therefore, though the DCSA program is more expensive, cost is unlikely to be a constraining factor in its implementation.

There is also the potential for conflicts and tensions between the DCSAs and current government officials that occupy some scientific advisory function within their departments and agencies. DCSAs will be able to work on files that may already have a subject-matter expert assigned, but their opinions could diverge on the topics and lead to uncertainty about the government position. There could also be accusations of bias in favour of the DCSA's own favoured policies if the DCSA plays a prominent role in developing "policy for science". However, we believe that maintaining the lack of decisionmaking role for the DCSAs will allow for clear differentiation between the advice versus the decision, which will be taken by ADMs and other government decision-makers.

Tensions could also emerge due to perceived DCSA duplication of the roles currently occupied by Chief Scientists and ADMs. Previous attempts at implementing science advice within departments have ended with either their conversion into managerial positions or were phased out of existence during departmental reorganizations (e.g., Enros 2013). Because of this, we have emphasized an "outsider" role for the DCSAs with a much greater focus on external engagement and outreach than previous advisors. In this way, the DCSA can complement the "insiders" within their departments who already provide internal scientific advice. Furthermore, the lack of managerial responsibilities will allow the DCSA to spend more time producing products rather than focusing on bureaucratic operations.

Another source of tension would be the public-facing role of the DCSA versus providing internal advice to decision-makers. Decision-makers may not wish to trust a public-facing DCSA as they may worry about confidentiality. They could also be reticent to work with the DCSA if they suspect criticism of their department's work in public reports. One way to alleviate these concerns is to implement a "no surprises" policy where DCSAs alert their DMs and ministers of their upcoming reports and statements. This way, DMs and ministers can prepare responses beforehand and allow for greater confidence in their DCSA.

Overall, despite these costs and potential tensions, we would argue that a DCSA program would be a net benefit for evidence-based policy making in Canada. If successfully implemented, it would lead to greater coordination within the government with regard to science policy, empower the CSA and its office to tackle important problems, and provide mechanisms to ensure that the best evidence is available to each department for its policy making process.

\section{Conclusion}

The arrival of the new CSA for Canada represents a golden opportunity to look at new ways of improving the impact science has in policy-making. Others have already suggested that the CSA be put in charge of a Four Agency Coordination Board and a National Advisory Council of Research 
and Innovation to help improve coordination of research within and beyond the federal government (Naylor et al. 2017). It is clear that the future CSA will need support within and beyond the government to be effective in the role.

Our proposed DCSA model, based on previous successes in New Zealand and the UK, would be a way to extend the influence of science advice and provide additional scientific expertise throughout government. We have endeavoured to show that its benefits outweigh its costs, how it could be implemented, and the timelines necessary for the endeavour. We also have provided examples of how science advice can succeed or fail, which illustrated that having access to ministers, parliamentarians, and senior policy-makers while being able to make recommendations is key, which is why we emphasized the challenge function of the DCSAs.

This is not to say that DCSAs with the CSA will resolve all the problems of disinformation leading to poor policy decisions. Our model partly addresses disinformation through its public outreach function, but there is only so much 17 individuals can do in a nation of over 36 million people. There is a substantial need to improve public scientific literacy to help the general public distinguish between good science and nonsense on stilts (Council of Canadian Academies 2014). To do so, there needs to be efforts to improve science education throughout the education system (Fenstein et al. 2013), which is not the jurisdictional purview of the federal government and will likely require investment and support over a much longer timeframe.

The DCSA program is just the first of many steps required to help ensure that the best evidence is available to both the public and policy-makers to ensure a full and open debate about what policies can and cannot do. Future work will need to be done to see how to ensure that the various efforts to improve both science policy advice and science education (e.g., Naylor et al. 2017) will be aligned so that science keeps its seat at the table, and is not sent away when it is inconvenient.

\section{Acknowledgements}

KDG and JNM would like to thank D. McKee, L. Chartrand, R. Chaloux, and R. Johnston for their contributions to the Mitacs Policy Hackathon on 11 May 2017, which helped inspire this paper. We would also like to thank Mitacs for their financial support through the Mitacs Canadian Science Policy Fellowship and the two anonymous reviewers that provided comments on the original draft.

\section{Author contributions}

JNM and KDG conceived and designed the study. JNM and KDG contributed resources. JNM and KDG drafted or revised the manuscript.

\section{Competing interests}

The authors have declared that no competing interests exist.

\section{Data accessibility statement}

All relevant data are within the paper.

\section{References}

Andresen MA, and Boyd N. 2010. A cost-benefit and cost-effectiveness analysis of Vancouver's supervised injection facility. The International Journal of Drug Policy, 21(1): 70-76. PMID: 19423324 DOI: 10.1016/j.drugpo.2009.03.004 
Auckland Regional Public Health Service. 2017. Submission on the health (fluoridation of drinking water) amendment bill [online]: Available from arphs.govt.nz/Portals/0/Signed_submission \%20Fluoridation\%20Amendment\%20Bill\%202017.pdf.

Australian Government. 2017. The chief scientist [online]: Available from chiefscientist.gov.au/about/ the-chief-scientist/.

Cabinet Social Policy Committee. 2017. Decision-making on the flouridation of drinking-water supplies [online]: Available from health.govt.nz/system/files/documents/pages/cabinetpaper-decision-making-fluoridation-drinking-water-supplies.pdf.

Canadian Food Inspection Agency. 2016. 2016-2017 Report on plans and priorities [online]: Available from inspection.gc.ca/about-the-cfia/accountability/reports-to-parliament/2016-17-rpp/ eng/1453472983491/1453472984734.

Comité d'éthique de la santé publique. 2012. Opinion on a project to fluoridate water. Government of Québec, Québec, Quebec. 13 p.

Council of Canadian Academies. 2014. Science culture: where Canada stands. The Expert Panel on the State of Canada's Science Culture, Council of Canadian Academies, Ottawa, Ontario.

Dooling K, and Rachlis M. 2010. Vancouver's supervised injection facility challenges Canada's drug laws. Canadian Medical Association Journal, 182(14): 1440-1444. PMID: 20805208 DOI: $10.1503 /$ cmaj. 100032

Dufour P, and de la Mothe J (Editors). 1993. Science and technology in Canada: Longman guide to world science and technology. Longman Group UK Ltd., Harlow, Essex.

Enros P. 2013. Environment of science: a history of policy for science in Environment Canada. Self-published. $266 \mathrm{p}$.

Fenstein NW, Allen S, and Jenkins E. 2013. Outside the pipeline: reimagining science education for non-scientists. Science, 340(6130): 314-317. PMID: 23599483 DOI: 10.1126/science.1230855

Geddes J. 2010. Injecting truth. Macleans, 123(33/34): 20-23 [online]: Available from macleans.ca/ news/canada/injecting-truth/.

Godlee F, Smith J, and Marcovitch H. 2011. Wakefield's article linking MMR vaccine and autism was fraudulent. British Medical Journal, 342: c7452. PMID: 21209060 DOI: 10.1136/bmj.c7452

Government of Canada. 2014. Directive on Open Government [online]: Available from tbs-sct.gc.ca/ $\mathrm{pol} /$ doc-eng. .aspx?id=28108.

Government of Canada. 2017a. Appointment: chief science advisor [online]: Available from appointments-nominations.gc.ca/slctnPrcs.asp? menu=1 \&lang=eng\&SelectionProcessId=A2E3CD929963-40FF-906A-D4550223C164.

Government of Canada. 2017b. Building a strong middle class: budget 2017 [online]: Available from budget.gc.ca/2017/docs/plan/budget-2017-en.pdf.

Gov.UK. 2017. Chief scientific advisers [online]: Available from gov.uk/government/groups/ chief-scientific-advisers. 
Grove R. 2006. Science policy. The Canadian encyclopedia [online]: Available from thecanadianencyclopedia.ca/en/article/science-policy/.

Health Canada. 2006. No new injection sites for addicts until questions answered says Minister Clement [online news release]: Available from canada.ca/en/news/archive/2006/09/no-newinjection-sites-addicts-until-questions-answered-says-minister-clement.html?=undefined\&.

Health Canada. 2008. Vancouver's INSITE service and other supervised injection sites: what has been learned from research?-final report of the expert advisory committee on supervised injection site research [online]: Available from canada.ca/en/health-canada/corporate/about-health-canada/reports-publications/ vancouver-insite-service-other-supervised-injection-sites-what-been-learned-research.html.

Health Canada. 2011. Guidelines for Canadian drinking water quality: guideline technical document-fluoride [online]. Available from: canada.ca/en/health-canada/services/publications/ healthy-living/guidelines-canadian-drinking-water-quality-guideline-technical-document-fluoride. html.

Hutchings JA, and Stenseth NC. 2016. Communication of science advice to government. Trends in Ecology \& Evolution, 31(1): 7-11. PMID: 26724100 DOI: 10.1016/j.tree.2015.10.008

Institut national de santé publique du Québec. 2007a. Water fluoridation: an analysis of the health benefits and risks. Government of Québec, Québec, Quebec. 41 p.

Institut national de santé publique du Québec. 2007b. Critique du livre «La fluoration Autopsie d'une erreur scientifique». Government of Québec, Québec, Quebec. 12 p. [online]: Available from assnat. qc.ca/Media/Process.aspx?MediaId=ANQ.Vigie.Bll.DocumentGenerique_71281\&process=Default\& token=ZyMoxNwUn8ikQ+TRKYwPCjWrKwg+vIv9rjij7p3xLGTZDmLVSmJLoqe/vG7/YWzz.

International Network on Government Science Advice (INGSA). 2017. INGSA homepage [online]: Available from ingsa.org.

Kerr T, Stoltz J, Tyndall MW, Li K, Zhang R, Montaner JS, et al. 2006a. Impact of a medically supervised safer injection facility on community drug use patterns: a before and after study. British Medical Journal, 332(7535): 220-222. PMID: 16439401 DOI: 10.1136/bmj.332.7535.220

Kerr T, Tyndall MW, Lai C, Montaner JS, and Wood E. 2006b. Drug-related overdoses within a medically supervised safer injection facility. The International Journal of Drug Policy, 17(5): 436-441. DOI: 10.1016/j.drugpo.2006.05.008

Kingdon JW. 2011. Agendas, alternatives and public policies. Longman, New York City, New York.

Kondro W. 2007. Health Minister Clement promises crackdown on illicit drug use. Canadian Medical Association Journal, 177(6): 559. PMID: 17711929 DOI: 10.1503/cmaj.071197

La Commission de la santé et des services sociaux. 2013. Étude de la pétition portant sur la fluoration de l'eau potable: observations, conclusions et recommandations. Direction des travaux parlementaires, Québec, Quebec.

Liberal.ca. 2015. Real change: a fair and open government [online]: Available from liberal.ca/ wp-content/uploads/2015/08/a-fair-and-open-government.pdf.

Marshall BDL, Milloy M-J, Wood E, Montaner JS, and Kerr T. 2011. Reduction in overdose mortality after the opening of North America's first medically supervised safer injecting facility: a retrospective 
population-based study. The Lancet, 377(9775): 1429-1437. PMID: 21497898 DOI: $10.1016 /$ S0140-6736(10)62353-7

McDonagh MS, Whiting PF, Wilson PM, Sutton AJ, Chestnutt I, Cooper J, et al. 2000. Systematic review of water fluoridation. British Medical Journal, 321(7265): 855-859. PMID: 11021861 DOI: $10.1136 / \mathrm{bmj} .321 .7265 .855$

Mitacs. 2017. Canadian science policy fellowship [online]: Available from mitacs.ca/en/programs/ canadian-science-policy-fellowship.

Moore D, and Poynton M. 2015. Review of the benefits and costs of water fluoridation in New Zealand. Report produced by the New Zealand Ministry of Health [online]: Available from health.govt.nz/system/files/documents/publications/review-benefits-costs-water-fluoridation-newzealand-apr16.pdf.

Naylor CD, Birgeneau RJ, Crago M, Lazaridis M, Malacrida C, McDonald AB, et al. 2017. Investing in Canada's future: strengthening the foundations of Canadian research. Advisory Panel for the Review of Federal Support for Fundamental Science, Ottawa, Ontario [online]: Available from sciencereview. ca/eic/site/059.nsf/vwapj/ScienceReview_April2017.pdf/\$file/ScienceReview_April2017.pdf.

Ntshotsho P, Prozesky HE, Elser KJ, and Reyers B. 2015. What drives the use of scientific evidence in decision making? The case of the South African Working for Water program. Biological Conservation, 184: 136-144. DOI: 10.1016/j.biocon.2015.01.021

Office of the Prime Minister of Canada. 2015. Minister of science mandate letter [online]: Available from pm.gc.ca/eng/minister-science-mandate-letter.

Office of the Prime Minister's Science Advisory Committee. 2014. Health effects of water fluoridation: a review of the scientific evidence [online]: Available from pmcsa.org.nz/wp-content/uploads/ Health-effects-of-water-fluoridation_Aug_2014_corrected_Jan_2015-copy.pdf.

Office of the Prime Minister's Science Advisory Committee. 2017. Terms of reference: Chief Science Advisor (CSA) [online]: Available from pmcsa.org.nz/wp-content/uploads/Terms-of-reference.pdf.

O'Hara K, and Dufour P. 2014. How accurate is the Harper government's misinformation? Scientific evidence and scientists in federal decision making. In How Ottawa spends 2014-2015: the Harper Government-good to go? Edited by GB Doern and C Stoney. McGill-Queen's University Press, Montreal, Quebec and Kingston, Ontario. pp. 178-191.

O’Mullane DM, Baez RJ, Jones S, Lennon MA, Petersen PE, Rugg-Gunn AJ, et al. 2016. Fluoride and oral health. Community Dental Health, 33: 69-99. PMID: 27352462 DOI: 10.1922/ CDH_3707O'Mullane31

Quirion R, Carty A, Dufour P, and Ramia J. 2016. Reflections on science advisory systems in Canada. Palgrave Communications, 2: 16048. DOI: 10.1057/palcomms.2016.48

Rivers N, and Jaccard M. 2009. Talking without walking: Canada's ineffective climate effort. In Governing the energy challenge: Canada and Germany in a multilevel regional and global context. Edited by B Erberlein and GB Doern. University of Toronto Press, Toronto, Ontario. pp. 285-313.

Science, Technology and Innovation Council. 2015. Mandate [online]: Available from stic-csti.ca/eic/ site/stic-csti.nsf/eng/h_00005.html. 
Senate Special Committee on Science Policy. 1970. A science policy for Canada (volume 1): a critical review, past and present [online]: Available from albertasenator.ca/flashblocks/data/BT\%20Science \%20and\%20Technology/Science\%20Policy\%20Vol\%201.pdf.

Shared Services Canada. 2016. Partner organizations by portfolio [online]: Available from canada.ca/ en/shared-services/corporate/partner-organizations/portfolio.html.

Steed G, and Millin L. 2005. Science Council of Canada. The Canadian encyclopedia [online]: Available from thecanadianencyclopedia.ca/en/article/science-council-of-canada/.

Sumner P, Vivian-Griffiths S, Boivin J, Williams A, Bott L, Adams R, et al. 2016. Exaggerations and caveats in press releases and health-related science news. PLoS ONE, 11(12): e0168217. PMID: 27978540 DOI: 10.1371/journal.pone.0168217

UK Government Office for Science. 2015. Chief Scientific Advisers and their officials: an introduction [online]: Available from gov.uk/government/uploads/system/uploads/attachment_data/file/426307/ 15-2-chief-scientific-advisers-and-officials-introduction.pdf.

UK Parliament. 2017. UK POSTnotes [online]: Available from parliament.uk/postnotes.

Wood E, Tyndall MW, Montaner JS, and Kerr T. 2006. Summary of findings from the evaluation of a pilot of medically supervised safer injecting facility. Canadian Medical Association Journal, 175(11): 1399-1404. PMID: 17116909 DOI: 10.1503/cmaj.060863 